\title{
Do visível ao invisível: a produção de engajamento na ONG Católicas pelo Direito de Decidir
}

\author{
Giovanna Paccillo dos Santos*, Rodrigo Ferreira Toniol.
}

\begin{abstract}
Resumo
Esta pesquisa de iniciação científica teve como objetivo acompanhar e analisar o grupo ativista católico e feminista de Católicas pelo Direito de Decidir (CDD) privilegiando os materiais encontrados ao longo da pesquisa de campo. Tal trabalho se trata do desdobramento da pesquisa anterior, iniciada em agosto de 2017. Para realização da pesquisa participei dos eventos públicos e reuniões particulares que organizaram, e adentrei suas relações com as mídias. Particularmente, optei por entender como a equipe de comunicação da ONG desempenhou um papel fundamental para que a organização se mantivesse ativa publicamente. A literatura em que me baseei é específica das áreas de gênero, religião, antropologia das materialidades, e também de áreas da mídia e midialogia. Procurei, desta forma, avançar em questões como os processos de engajamento e captação de interesse, de formação de sujeitos políticos, e também nas diferentes formas em que o grupo se constitui e é constituído, simultaneamente, por uma série de relações de aliança, disputa, e confronto, mostrando assim, que Católicas está inserida numa rede ampla de atores e afetos.
\end{abstract}

\section{Palavras-chave: \\ Católicas pelo Direito de Decidir, dispositivos de engajamento, mídias.}

\section{Introdução}

O trabalho de pesquisa que aqui descrevo constitui o desdobramento de minha primeira iniciação científica, iniciada em 2017. O grupo de Católicas pelo Direito de Decidir (CDD) é uma ONG católica-feminista que têm, entre seus principais objetivos, a descriminalização do aborto. Ao realizar entrevista com o grupo bem como acompanha-las em suas mídias sociais, reuniões e eventos, investiguei as formas pelas quais a organização conseguia não somente persistir ao longo do tempo apesar do formato já ultrapassado das ONGs - mas também se tornar cada vez mais atuante publicamente. Atenta a essa questão, me orientei pelas estratégias de engajamento da ONG, e pude dimensionar um processo pelo qual Católicas pelo Direito de Decidir passou entre os anos de 2012 a 2018: a contratação de uma equipe de comunicação. Este trabalho versa sobre as diversas vezes em que a equipe de comunicação ocupou um papel fundamental para a visibilidade de suas propostas e o engajamento de outras pessoas com o grupo.

\section{Resultados e Discussão}

Ao realizar entrevista com as integrantes de Católicas, perguntei o que elas consideravam como ponto de virada para a maior visibilidade que o grupo vinha alcançando. A resposta do grupo foi: a contratação da equipe de Comunicação e um tratamento melhor com redes sociais e mídias. Pensei então a relação do grupo com as mídias, entendidas como um "meio" num sentido amplo, ou seja, "todos os instrumentos histórica e culturalmente situados - como pinturas, esculturas, fotografias, filmes ou sites - que tornam uma imagem visível e tangível sob as condições de suas potencialidades e propriedades tecnológicas particulares"1. A imagem requer um meio que assuma sua presença, como o são as fotografias e vídeos. Esses também são os meios pelos quais as imagens podem ser compartilhadas e reproduzidas.

Percebi que além de filmarem e compartilharem os eventos promovidos pela ONG e suas participações públicas, o grupo começava a produzir seu próprio conteúdo.

O canal de youtube de Católicas contava com vídeos semanais com todo tipo de novidade. No final de 2016, a ONG lançou videoclipes de hip-hop feminista que falavam sobre a temática do Estado Laico e se opunham ao fundamentalismo religioso. Para além do conteúdo das músicas, todos os clipes foram pensados, dirigidos e gravados pela equipe de Comunicação de Católicas, evidenciando que o grupo visava, através da criação de novos formatos e linguagem angariar atenção de novos públicos. A equipe de Católicas também produziu minidocumentários sobre hiv/AIDs, a ADPF 442, e sobre saúde da mulher, conversando com outros grupos ativistas; além da série "babado laico" que chamava atenção para possibilidades de se viver a fé.

\section{Conclusões}

A internet representa uma das formas pela qual a ONG se publiciza. Não digo, no entanto, que essa é uma das formas de Católicas adentrar o espaço público e produzir engajamento. Ao contrário, a noção de que existe uma religião, um grupo, uma organização fechada, que "invade" a esfera pública é, como coloca o antropólogo Joanildo Burity (2018), mais uma aspiração iluminista do que algo factível e observável na realidade. Relegar a religião ao âmbito privado não significa que estas de fato estejam. Como aponta o antropólogo Emerson Giumbelli (2014), interessa-nos antes "compreender as modalidades da presença da religião na sociedade, partindo da constatação de que essa presença é pública" (GIUMBELLI, 2014, p.13). A religião, os grupos religiosos estão nas ruas, nas praças, em audiências públicas no STF, mas também nos meios de comunicação, novelas em horário nobre e na internet. Com a equipe de comunicação, a atuação de Católicas passou a engajar outro tipo de público, e a envolver mais àqueles que já as acompanhavam.

\section{Agradecimentos}

Agradeço ao CNPq pelo financiamento de minha pesquisa e ao meu orientador, prof. Dr. Rodrigo Toniol.

${ }^{1}$ MEYER, Birgit. Picturing the Invisible: Visual culture and the study of religion. In: Method and theory in the study of religion 27, 333-360, 2015 